\title{
Microwave-Assisted Rapid Preparation of Nano-ZnO/Ag Composite Functionalized Polyester Nonwoven Membrane for Improving Its UV Shielding and Antibacterial Properties
}

\author{
Dongfeng Shao ${ }^{1(D)}$ and Qufu Wei ${ }^{2, *}$ \\ 1 Changzhou Vocational Institute of Textile and Garment, Changzhou 213164, China; syx3313@163.com \\ 2 Key Laboratory of Eco-Textiles, Ministry of Education, Jiangnan University, Wuxi 214122, China \\ * Correspondence: qfwei@jiangnan.edu.cn; Tel.: +86-510-8591-2007
}

Received: 9 July 2018; Accepted: 8 August 2018; Published: 11 August 2018

\begin{abstract}
The cost and efficiency of preparing $\mathrm{ZnO} / \mathrm{Ag}$ composite functional polyester membrane affect their application, for which a rapid microwave-assisted method was studied for coating $\mathrm{ZnO} / \mathrm{Ag}$ composite nanoparticles on polyester nonwoven. The surface morphology, crystalline structure, and surface chemistry of the uncoated and coated polyester nonwoven was investigated by X-ray diffractometer (XRD), scanning electron microscopy (SEM), Fourier transform infrared spectroscopy (FT-IR), energy-dispersive spectroscopy (EDS), X-ray photoelectron spectroscopy (XPS), and thermogravimetric (TG), respectively. Washing stability, ultraviolet properties, and antibacterial properties of before and after treatment polyester nonwoven were also investigated. The results indicated that $\mathrm{Ag} / \mathrm{ZnO}$ composite nanoparticles were successfully deposited on polyester nonwoven surface. The amount of silver nitrate added in reaction has an important effect on the morphology and structure of $\mathrm{Ag} / \mathrm{ZnO}$ composite on the surface of polyester fiber. The washing experiment results show that the $\mathrm{ZnO} / \mathrm{Ag}$ composite functional polyester nonwoven fabric prepared by this method exhibits good washing durability after 90 min of washing. The results of UV transmission analysis showed that polyester nonwoven has an obvious increase in ultraviolet resistant properties after $\mathrm{Ag} / \mathrm{ZnO}$ composite coating. When $0.2 \mathrm{~g}$ of silver nitrate was added into $100 \mathrm{~mL}$ of the reaction solution, the mean ultraviolet protection factor (UPF) of the treated polyester nonwoven reached a maximum of 219.8. The antibacterial results showed that the coated nonwoven against Escherichia coli and Staphylococcus aureus was about $94.5 \%$ and $96.6 \%$, respectively, showing very good antibacterial properties.
\end{abstract}

Keywords: polyester; $\mathrm{ZnO}$; Ag; microwave assistant

\section{Introduction}

Polyester nonwoven are widely used in automotive interior decoration, garment linings, medical materials, and filter materials because of their high flexibility, good thermal stability, corrosion resistance, and strong mechanical properties [1]. However, some shortcomings, such as poor hygroscopicity, easily generates static charge, and lack of antibacterial and UV shielding properties, affect its application effect.

In recent years, nano $\mathrm{ZnO} / \mathrm{Ag}$ composite functional polyester nonwoven has been widely concerned because of its excellent optical and electrical properties. Nano $\mathrm{ZnO} / \mathrm{Ag}$ composite not only endow UV shielding, antistatic, anti-bacterial, and photocatalytic properties to polyester fabric [2,3], but also extend the application of polyester fabric in flexible transparent electrode [4-6] and flexible nanogenerators [7]. Magnetron sputtering [8,9] and hydrothermal methods [10] have been successfully 
used to prepare nano $\mathrm{ZnO} / \mathrm{Ag}$ composite functional polyester fabric. However, among these methods, magnetron sputtering requires two sputtering targets and many operational steps. Hydrothermal method needs to deposit $\mathrm{ZnO}$ seed or indium tin oxides (ITO) layer on the surface of polyester, and then nano $\mathrm{ZnO} / \mathrm{Ag}$ composite can grow on $\mathrm{ZnO}$ seed or ITO layer under hydrothermal conditions, which take a long time. Therefore, it is necessary to study a simple and rapid method for preparing nano $\mathrm{ZnO} / \mathrm{Ag}$ composite functional polyester nonwoven to meet the needs of industry.

Different technologies have been used to study the rapid preparation of nano $\mathrm{ZnO}$ or nano silver functional textiles. Microwave-assisted has received wide attention because of some unique advantages. For example, there is no direct contact between the reaction and the energy source during microwave heating, which acts directly on the molecule, and the heating rate is fast, the reaction is uniform, and so on [11]. It is successfully used to prepare $\mathrm{ZnO}$ functional cotton fabric [12,13], silver nanoparticles coated bamboo pulp fabric [14], and silver nanoparticles deposited viscose fibers [15] in a short time. In addition, a one-step preparation method of nano $\mathrm{ZnO}$ or nano Ag functional polyester has been reported. Hajar Poortavasoly, et al., reported that polyester fabric was surface modified with triethanolamine and simultaneously surface deposited $\mathrm{ZnO}$ at $130{ }^{\circ} \mathrm{C}$ about $1 \mathrm{~h} \mathrm{[16].} \mathrm{Also,} \mathrm{nano} \mathrm{Ag} \mathrm{was} \mathrm{deposited} \mathrm{on} \mathrm{the} \mathrm{polyester} \mathrm{fabric} \mathrm{surface} \mathrm{with} \mathrm{the} \mathrm{same} \mathrm{method} \mathrm{under} \mathrm{the}$ same conditions [17]. These studies provide a good idea for us to prepare nano $\mathrm{ZnO} / \mathrm{Ag}$ composite functional polyester nonwoven quickly. Polyester nonwoven surface can be treated by triethanolamine and simultaneously nano $\mathrm{ZnO} / \mathrm{Ag}$ composite be rapidly deposited on polyester nonwoven surface with microwave assistant.

In this study, this method is used for the rapid preparation of nano $\mathrm{ZnO} / \mathrm{Ag}$ composite functional polyester nonwoven. The surface morphology, and physical and chemical structure of polyester nonwoven before and after treatment were investigated. Washing stability, ultraviolet properties, and antibacterial properties of polyester nonwoven after treatment were also studied.

\section{Materials and Methods}

\subsection{Materials}

Meltblown polyester nonwoven $\left(52 \mathrm{~g} / \mathrm{m}^{2}\right)$ was provided by Jiangsu Chuangyuan Interlinings Co., Ltd., Jiangsu, China. Samples were washed with ethanol and distilled water before use. Zinc nitrate hexahydrate, silver nitrate, and triethanolamine were purchased from Shanghai Chemical Reagent Co. shanghai, China. All the reagents were used as received. Staphylococcus aureus (ATCC 6538) and Escherichia coli (ATCC 8099) was from the Analysis and Testing Center of College of Textile and Clothing Engineering of Soochow University (Soochow, China).

\subsection{Preparation of $\mathrm{ZnO}-\mathrm{Ag}$ Composite Coated Polyester Nonwoven}

$\mathrm{ZnO}-\mathrm{Ag}$ composite coated polyester nonwoven was prepared as is illustrated in Figure 1. First, $2.97 \mathrm{~g}$ zinc nitrate hexahydrate was first dissolved in $80 \mathrm{~mL}$ distilled water under stirring. Then, $20 \mathrm{~mL}$ triethanolamine was slowly added, and stirred at room temperature to obtain a clear solution. Next, $0.1 \mathrm{~g}-0.3 \mathrm{~g}$ silver nitrate was dissolved in the above solution under stirring. Samples of various treatments are shown in Table 1 . Further, a $6 \mathrm{~cm} \times 6 \mathrm{~cm}$ polyester nonwoven sample was immersed into the mixture solution, and then placed into the microwave oven (P80D23N1L, Galanz, Shunde, China) with a frequency of $2450 \mathrm{MHz}$ and a power of $800 \mathrm{~W}$. The reaction was performed for $10 \mathrm{~min}$ in the microwave oven under medium and high fire. During the microwave treatment, checked every two minutes to make sure that the sample was immersed in the solution and kept the sample flat and wrinkle free. Finally, the treated sample was taken out of the solution, washed with distilled water, and then dried at $80{ }^{\circ} \mathrm{C}$. 
Table 1. Samples prepared under different processing conditions.

\begin{tabular}{ccccc}
\hline Sample & $\mathbf{H}_{\mathbf{2}} \mathbf{O}(\mathbf{m L})$ & Triethanolamine $(\mathbf{m L})$ & $\mathbf{Z n}\left(\mathrm{NO}_{3}\right)_{\mathbf{2}} \cdot \mathbf{6} \mathbf{H}_{\mathbf{2}} \mathbf{O}(\mathbf{g})$ & $\mathbf{A g N O}_{\mathbf{3}}(\mathbf{g})$ \\
\hline Control & 0 & 0 & 0 & 0 \\
$1 \#$ & 80 & 20 & 0 & 0 \\
$2 \#$ & 80 & 20 & 2.97 & 0 \\
$3 \#$ & 80 & 20 & 2.97 & 0.1 \\
$4 \#$ & 80 & 20 & 2.97 & 0.2 \\
$5 \#$ & 80 & 20 & 2.97 & 0.3 \\
\hline
\end{tabular}
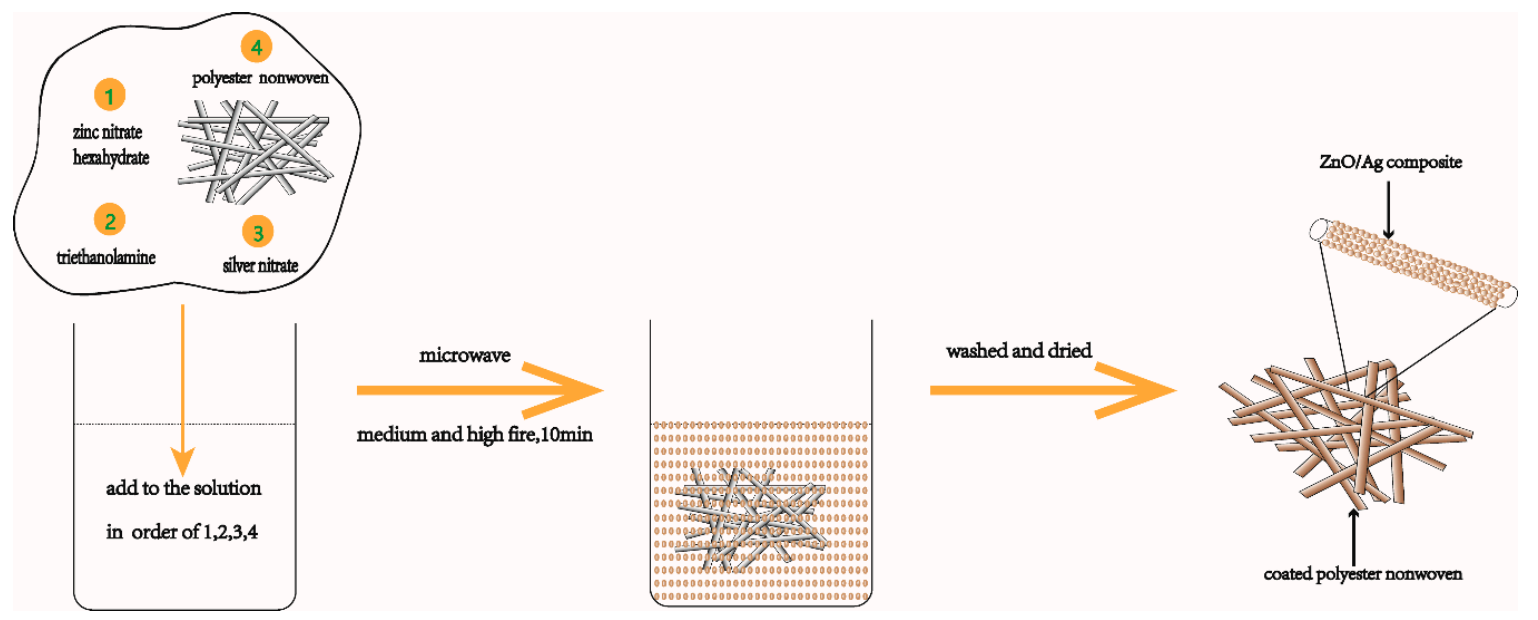

Figure 1. Schematic of rapid $\mathrm{ZnO} / \mathrm{Ag}$ composite functionalization of polyester nonwoven by microwave-assisted.

\subsection{Characterizations}

Scanning electron microscopy (SEM, S-4800, Hitachi, Tokyo, Japan) was used to examine the surface morphology of the polyester nonwoven and $\mathrm{ZnO} / \mathrm{Ag}$ composite coated polyester nonwoven. The magnification of the SEM is 2000 and 20,000, respectively.

X-ray diffractometer (XRD, D/max2500PC, Rigaku, Tokyo, Japan) was used to investigate the phase and crystalline state of before and after treatment polyester nonwoven. The XRD patterns were recorded using a Cu Karadiation $(\mathrm{I}=1.54056 \AA$ ) $)$.

Surface chemical of before and after treatment polyester nonwoven was examined by Fourier transform infrared spectroscopy (FT-IR, IS50, ThermoFisher, MA, USA), energy-dispersive spectroscopy (EDS, quantax400, Bruker, Berlin, Germany), and X-ray photoelectron spectroscopy (XPS, Escalab 250Xi, ThermoFisher, MA, USA). The FT-IR absorption spectrum was recorded in the range of $4000-400 \mathrm{~cm}^{-1}$ with 32 scans at a resolution of $4 \mathrm{~cm}^{-1}$. Energy-dispersive spectroscopy was used to characterize the elemental distribution of after treatment polyester nonwoven. XPS were recorded using amonochromated $\mathrm{Al} \mathrm{K} \alpha \mathrm{X}$-ray source $(1486.7 \mathrm{eV})$. The size of the X-ray beam was $200 \mu \mathrm{m}$.

Thermogravimetric (TG, Q500, TA Instruments, DE, USA) is used to detect the thermal stability of the treated samples. Thermo gravimetric measurements are performed from 50 to $595{ }^{\circ} \mathrm{C}$ using a linear heating rate of $10^{\circ} \mathrm{C} / \mathrm{min}$ in a nitrogen atmosphere.

\subsection{Washing Stability}

Washing stability of $\mathrm{ZnO} / \mathrm{Ag}$ composite coated polyester nonwoven was assessed by washing experiment using a domestic washing machine. The samples were dried after washing for 30, 60, and $90 \mathrm{~min}$, then weighed, after which the washing stability was evaluated. A typical $30 \mathrm{~min}$ washing procedure was as follows: $10 \mathrm{~g} \mathrm{ZnO} / \mathrm{Ag}$ composite coated polyester nonwoven washed with $5 \mathrm{~g}$ of 
standard detergent in $4 \mathrm{~L}$ of water for $30 \mathrm{~min}\left(30^{\circ} \mathrm{C}\right)$. It was dehydrated and then washed with $4 \mathrm{~L}$ of water for $2 \mathrm{~min}$ under room temperature. Finally, the sample was dried at $60^{\circ} \mathrm{C}$. The washing stability was evaluated by the reduction percentage of weight between the washed sample and control sample.

\subsection{Ultraviolet Resistant Properties}

Ultraviolet transmittance analyzer (UV-1000F, Lapsphere, NH, USA) was used to test ultraviolet resistant properties of polyester nonwoven before and after coating according to GB/T 18830-2009 [18]. The ultraviolet transmittance was recorded in the range of $290-400 \mathrm{~nm}$. The results of ultraviolet resistant property were evaluated by solar UV-A spectral transmittance (T(UVA)), solar UV-B spectral transmittance (T(UVB)), and ultraviolet protection factor (UPF). Each sample was tested four times at different areas, and the average values were obtained.

\subsection{Antibacterial Properties}

The antibacterial properties of before and after treated polyester nonvowen were evaluated using the shake flask method against Staphylococcus aureus and Escherichia coli. Each fresh bacterial strain was cultured under the conditions of nutrient agar $\left(37^{\circ} \mathrm{C}, 18 \mathrm{~h}\right)$. Then, inoculate fresh bacteria in a nutrient solution at $37^{\circ} \mathrm{C}$ for $18 \mathrm{~h}$, and diluted to a suspension $\left(1 \times 10^{4} \sim 9 \times 10^{4} \mathrm{CFU} / \mathrm{mL}\right)$ with phosphate buffer saline. CFU is colony forming units. The treated polyester samples and control samples were each cut into a size of $0.5 \mathrm{~cm} \times 0.5 \mathrm{~cm}$ and sterilized in an autoclave at $121^{\circ} \mathrm{C}$ for $15 \mathrm{~min}$. Next, $70 \mathrm{~mL}$ phosphate buffered saline, $0.75 \mathrm{~g}$ sample, and $5 \mathrm{~mL}$ the diluted bacteria suspension were sequentially added to a erlenmeyer flask $(250 \mathrm{~mL})$. It was then shaken at $150 \mathrm{rpm}$ for $18 \mathrm{~h}$ at room temperature. Next, $1 \mathrm{~mL}$ bacteria solution collected from each erlenmeyer flask was diluted 10 times, 100 times, and 1000 times, respectively. Finally, bacterial suspension of different dilutions was inoculated on agar medium for $24 \mathrm{~h}$ at $37^{\circ} \mathrm{C}$, and colonies were counted. The antibacterial properties were evaluated by the reduction percentage of bacteria colonies between the treated sample and control samples.

\section{Results and Discussion}

\subsection{Crystalline Structure Analysis}

Figure 2a shows the X-ray diffraction (XRD) patterns of polyester nonwoven. As is shown in Figure $2 \mathrm{a}$, the reflection peaks at $2 \theta=17.4,22.7$ and 25.4 correspond to (100), (002), and (101) planes of polyester nonwoven, respectively. Figure $2 \mathrm{~b}-\mathrm{d}$ are all $\mathrm{XRD}$ patterns of $\mathrm{ZnO} / \mathrm{Ag}$ composite coated polyester nonwoven. Their difference is that the amount of silver nitrate added in the preparation process is $0.1 \mathrm{~g}, 0.2 \mathrm{~g}$, and $0.3 \mathrm{~g}$, respectively. From Figure $2 \mathrm{~b}$, it can be seen that a series of peaks at $2 \theta=31.7^{\circ}, 34.4^{\circ}, 36.2^{\circ}, 38.1^{\circ}, 44.3^{\circ}, 56.6^{\circ}, 64.4^{\circ}$, and $77.5^{\circ}$ are detected in the XRD curve, besides the reflection peaks of polyester nonwoven. The peak at $2 \theta=31.7^{\circ}, 34.4^{\circ}, 36.2^{\circ}$, and $56.6^{\circ}$ contribute to (100), (002), (101), and (110) planes of the hexagonal wurtzite $\mathrm{ZnO}$, respectively (JCPDS 36-1451) [19]. The peak appearing at $2 \theta=38.1^{\circ}$ and $44.3^{\circ}, 64.4^{\circ}$, and $77.5^{\circ}$ correspond to the (111), (220), (200), and (311) crystal plane of silver, respectively (JCPDS 04-0783) [19]. These results indicate that the $\mathrm{ZnO} / \mathrm{Ag}$ composite is successfully deposited on the surface of polyester nonwoven under this conditions. Also, it can be seen that the reflection peak intensity of the (100), (002), and (101) crystal planes of polyester nonwoven decreases slightly, which is attributed to the decrease in crystallinity of polyester nonwoven caused by the reaction of triethanolamine with polyester. Compared with Figure $2 b$, it can be observed that there is the increase of the reflection peak intensity of the (111), (220), (200), and (311) crystal plane of silver, as is shown in Figure 2c,d. This is a result of the increase in silver nitrate content in the reaction, and more silver is reduced by triethanolamine, causing crystal growth of silver on the nonwoven surface. In addition, it can be seen that the crystallinity of silver in the $\mathrm{ZnO} / \mathrm{Ag}$ composite deposited on the nonwoven surface in Figure $2 \mathrm{c}$ is better than that of the silver in Figure 2d. This implies that the amount of silver nitrate affects the structure of $\mathrm{ZnO} / \mathrm{Ag}$ composite on the nonwoven surface. 


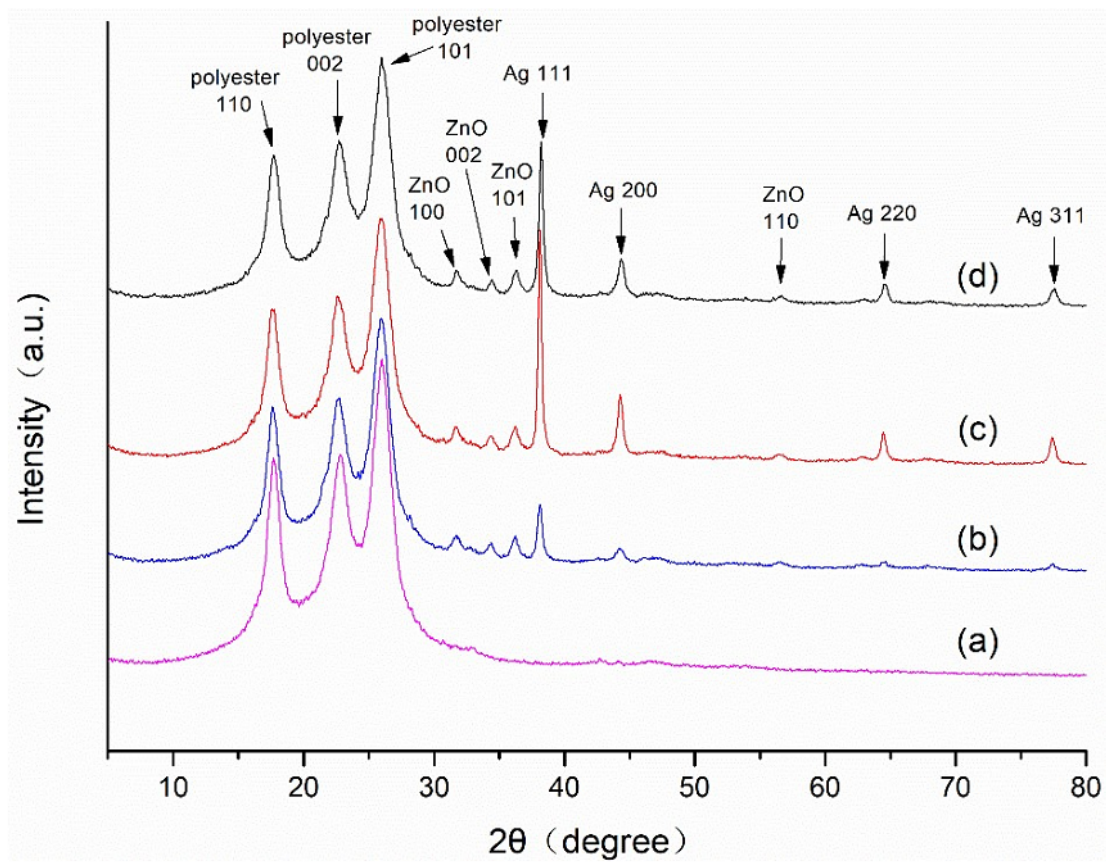

Figure 2. X-ray diffractometer (XRD) patterns of (a) polyester nonwoven; (b) ZnO/Ag composite coated polyester nonwoven (3\#); (c) ZnO/Ag composite coated polyester nonwoven (4\#); and (d) $\mathrm{ZnO} / \mathrm{Ag}$ composite coated polyester nonwoven (5\#).

\subsection{Surface Morphology Analysis}

The SEM images of polyester nonwoven are shown in Figure 3a. It can be seen that the polyester fiber surface appears to be relatively smooth, and a small number of elongated rods are distributed on the fiber surface. Compared with untreated polyester fiber, it can be observed that the surface of the polyester fiber showed significant changes after $\mathrm{ZnO} / \mathrm{Ag}$ composite coating, as is illustrated in Figure $3 b-d$. From Figure 3b, it can be seen that most of the surface of the fiber is evenly wrapped by particles. These particles are divided into two layers. The bottom particles are irregular granules with the size range of 50-260 nm, but the upper part is spherical particles with the size of $110-380 \mathrm{~nm}$, and the average diameter is about $320 \mathrm{~nm}$. The irregular particles are because the reaction of triethanolamine with the polyester will be grafted onto the surface of the fiber [17]. Similar to the principle that $\mathrm{C}_{2} \mathrm{H}_{2} \mathrm{O}_{4}$ controls the formation of irregular block $\mathrm{ZnO}$ [20], several hydroxyl groups grafted on the fiber surface adsorb $\mathrm{Zn}^{2+}$ form templates and control irregular $\mathrm{ZnO}$ granules generation on the surface of the fiber. When the fiber surface triethanolamine is covered with particles and the silver ions are reduced to $\mathrm{Ag}$ on the surface of the particles, some $\mathrm{ZnO}$ seeds are then deposited on the surface of $\mathrm{Ag}$ [21]. With the increase of the reaction time, $\mathrm{ZnO}$ grows on the seeds to form the upper spherical $\mathrm{ZnO} / \mathrm{Ag}$ composite structure. However, under the condition of $0.2 \mathrm{~g}$ silver nitrate being added, the particles coated on the surface of the fiber are more uniform, as is illustrated in Figure 3c. These particles also have two layers, but the size of spherical particles in the upper layer ranges from $170 \mathrm{~nm}$ to $330 \mathrm{~nm}$, and the average particle size is about $260 \mathrm{~nm}$. When $0.3 \mathrm{~g}$ of silver nitrate was added, the surface of the fiber had only spherical composite particles with sizes ranging from 150 to $440 \mathrm{~nm}$, and the average size is about $270 \mathrm{~nm}$, as is shown in Figure 3d. This is because the silver nitrate content in the solution increases, and more silver ions are reduced to silver on the fiber surface, which hinders the effect of triethanolamine on the growth morphology of $\mathrm{ZnO} / \mathrm{Ag}$ composite on the fiber surface. Combined with previous XRD analysis and SEM image, it was further proved that the amount of silver nitrate added in the coating reaction had a significant effect on the structure of the $\mathrm{ZnO} / \mathrm{Ag}$ composite particles deposited on the nonwoven surface. 


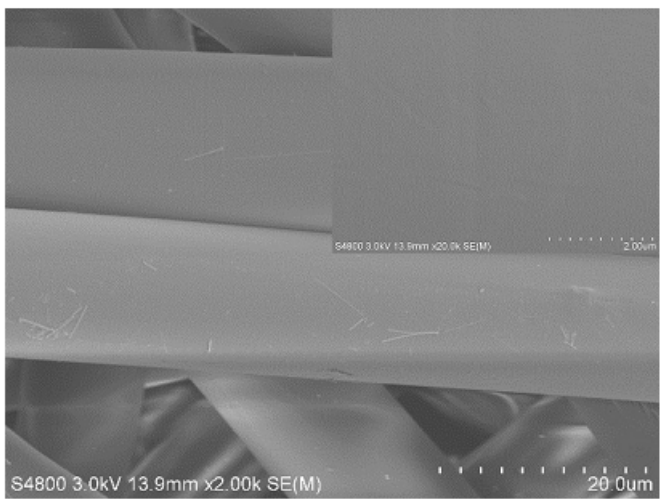

(a)

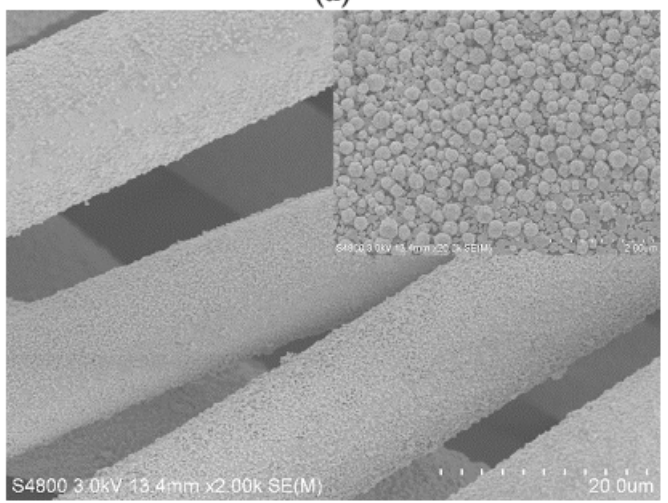

(c)

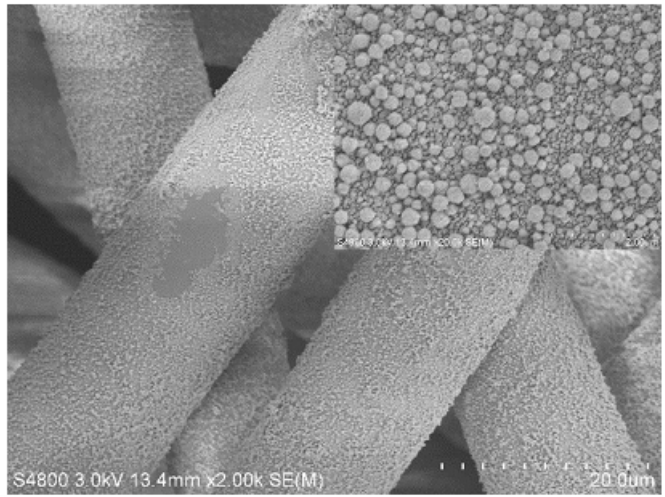

(b)

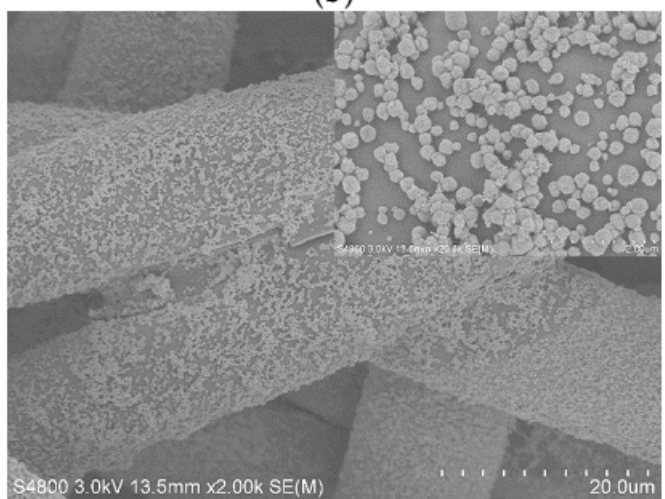

(d)

Figure 3. Scanning electron microscopy (SEM) images of (a) polyester nonwoven; (b) $\mathrm{ZnO} / \mathrm{Ag}$ composite coated polyester nonwoven (3\#); (c) $\mathrm{ZnO} / \mathrm{Ag}$ composite coated polyester nonwoven (4\#); and (d) $\mathrm{ZnO} / \mathrm{Ag}$ composite coated polyester nonwoven (5\#).

\subsection{Surface Chemistry Analysis}

In order to explore the mechanism of $\mathrm{ZnO} / \mathrm{Ag}$ composite functional polyester, the infrared spectra of polyester, triethanolamine treated polyester, $\mathrm{ZnO}$ coated polyester, and $\mathrm{ZnO} / \mathrm{Ag}$ composite coated polyester were analyzed, respectively. Figure 4 shows the FT-IR spectra of polyester nonwoven and triethanolamine treated polyester nonwoven. As is shown in Figure $4 \mathrm{a}$, the band at $3439 \mathrm{~cm}^{-1}$ is ascribed to $-\mathrm{OH}$ group, while those at $2961 \mathrm{~cm}^{-1}$ and $1454 \mathrm{~cm}^{-1}$ are assigned to the $\mathrm{C}-\mathrm{H}$ stretching vibration [22]. The band at $1730 \mathrm{~cm}^{-1}$ is attributed to the stretching vibration of the $\mathrm{C}=\mathrm{O}$ bond. The band at $1577 \mathrm{~cm}^{-1}$ is represented to the $\mathrm{C}-\mathrm{H}$ bond stretching vibration of the phenyl ring. The band at $1410 \mathrm{~cm}^{-1}$ is attributed to the C-C phenyl ring stretching. The band at $1239 \mathrm{~cm}^{-1}$ and $1095 \mathrm{~cm}^{-1}$ is due to $\mathrm{C}-\mathrm{O}$ stretching [23]. From Figure $4 \mathrm{~b}$, it can be seen that the band of triethanolamine treated polyester nonwoven changed at $3431 \mathrm{~cm}^{-1}, 2921 \mathrm{~cm}^{-1}$, and $1735 \mathrm{~cm}^{-1}$ compared with that of polyester nonwoven. This is due to the treatment of the polyester by triethanolamine, which causes some of the triethanolamine molecules to be grafted onto the surface of the polyester [17], causing subtle changes in the bonds such as $\mathrm{C}=\mathrm{O}, \mathrm{C}-\mathrm{H}$, and $\mathrm{O}-\mathrm{H}$. Figure 5a shows the FT-IR spectra of $\mathrm{ZnO}$ coated polyester. Compared with the spectra of polyester nonwoven and triethanolamine treated polyester nonwoven, there are obvious shifts in the band at $3441 \mathrm{~cm}^{-1}, 2959 \mathrm{~cm}^{-1}, 1730 \mathrm{~cm}^{-1}, 1239 \mathrm{~cm}^{-1}$, $1094 \mathrm{~cm}^{-1}$, and $723 \mathrm{~cm}^{-1}$, and the new band is found at $432 \mathrm{~cm}^{-1}$, as shown in Figure $5 \mathrm{a}$. The new band at $432 \mathrm{~cm}^{-1}$ was attributed to the band of $\mathrm{Zn}-\mathrm{O}$ vibrations [24]. Other infrared absorption peak shifts are due to polyester ester groups reacting with hydroxyl groups of triethanolamine. However, after $\mathrm{ZnO} / \mathrm{Ag}$ composite coated polyester nonwoven, the band of $\mathrm{C}=\mathrm{O}$ stretching vibration bond at $1735 \mathrm{~cm}^{-1}, \mathrm{C}-\mathrm{O}$ stretching bond at $1237 \mathrm{~cm}^{-1}$ and $1090 \mathrm{~cm}^{-1}$ are shifted, as is shown in Figure $5 \mathrm{~b}$. This is because the hydroxyl of triethanolamine reacts with silver nitrate to form the aldehyde group 
$(\mathrm{C}=\mathrm{O})$, and the aldehyde group may continue to react with silver nitrate to form a carboxyl group $(\mathrm{O}=\mathrm{C}-\mathrm{O})$. Also, the band of $\mathrm{Zn}-\mathrm{O}$ vibrations at $432 \mathrm{~cm}^{-1}$ obviously weakened and offset to $421 \mathrm{~cm}^{-1}$, which may be because silver doped $\mathrm{ZnO}$ affects the $\mathrm{Zn}-\mathrm{O}$ vibrations.

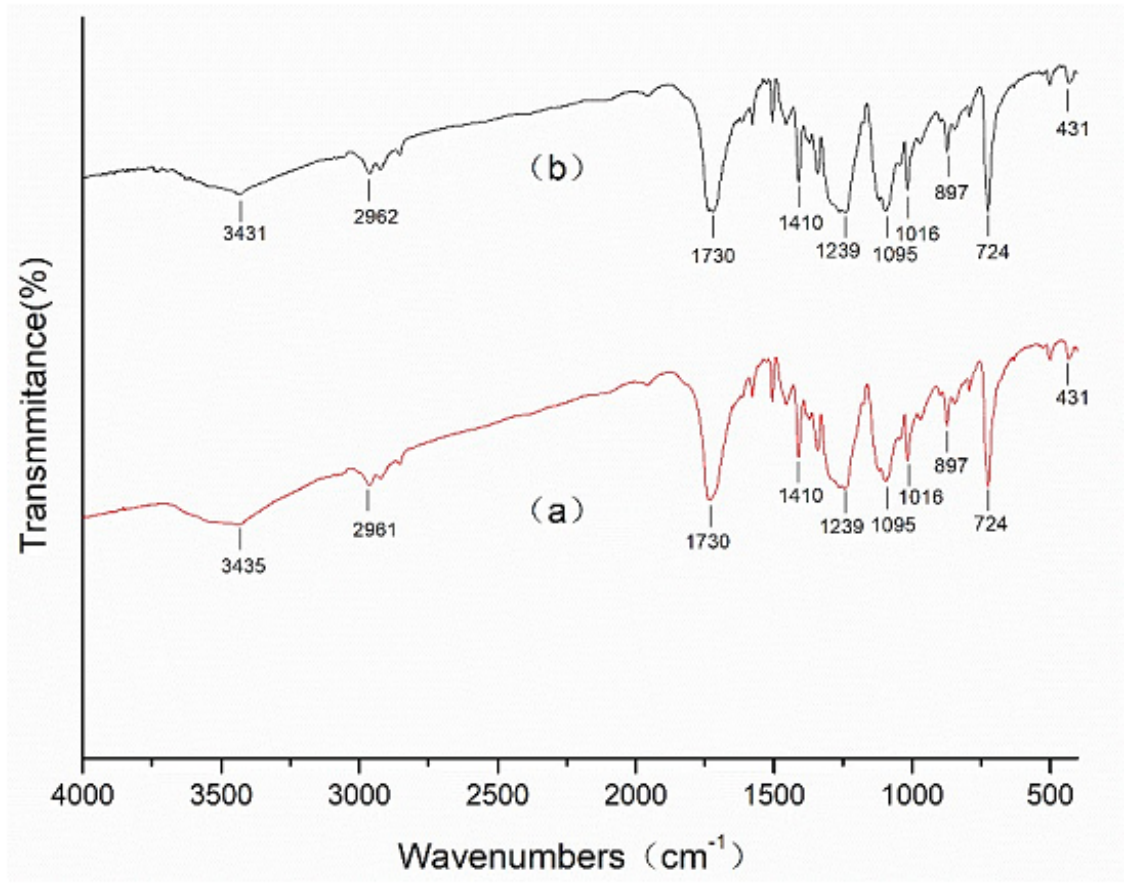

Figure 4. Fourier transform infrared spectroscopy (FTIR) spectra of (a) polyester nonwoven; (b) triethanolamine treated polyester nowoven (1\#).

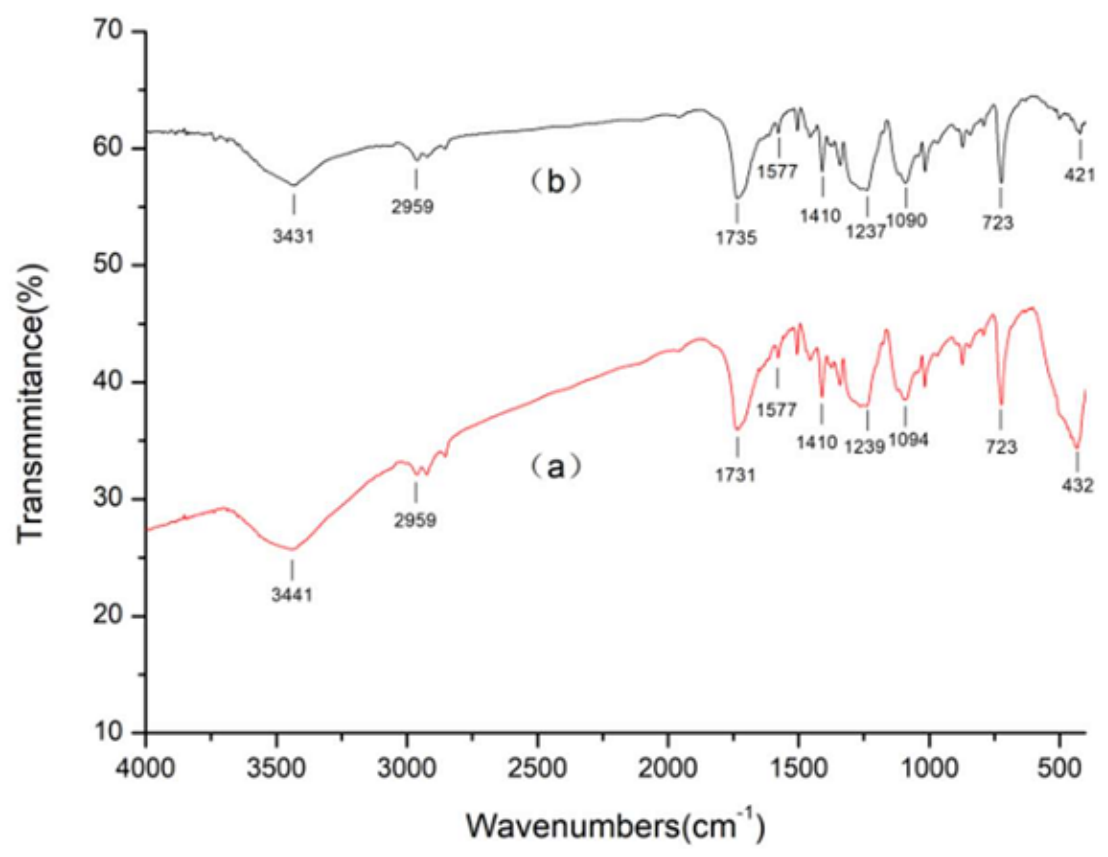

Figure 5. FTIR spectra of (a) $\mathrm{ZnO}$ coated polyester nonwoven (2\#); (b) $\mathrm{ZnO} / \mathrm{Ag}$ composite coated polyester nowoven (3\#).

X-ray mapping images of $\mathrm{ZnO} / \mathrm{Ag}$ composite coated polyester nonwoven (4\# sample) are presented in Figure 6. It can be seen that the zinc element is evenly distributed on the fiber surface and 
the fiber gap, while silver elements are mainly distributed on the surface of fibers. This indicates that Ag might be encapsulated by $\mathrm{ZnO}$ on the nonwoven surface [25].

XPS analysis of the content and valence of each element in the $\mathrm{ZnO} / \mathrm{Ag}$ composite on the surface of nonwoven is crucial to the study of the properties of the materials, just like the surface of nitrogen-coated silver nanoparticles was analyzed by XPS and its antibacterial activity was explored [26]. Figure 7 presents X-ray photoelectron spectroscopy of $\mathrm{ZnO} / \mathrm{Ag}$ composite coated polyester nonwoven prepared with $0.2 \mathrm{~g}$ silver nitrate. From Figure $7 \mathrm{a}$, it can be seen that there are five characteristic peaks of $\mathrm{C}, \mathrm{Ag}, \mathrm{N}, \mathrm{O}$, and $\mathrm{Zn}$ from the full spectrum. Among them, the atomic content percentages of C1s, Ag3d, N1s, O1s, and Zn2p were 43.52\%, 1.57\%, 2.44\%, 29.61\%, and 22.87\%, respectively. The high-resolution XPS spectra of Ag3d and Zn2p in the Ag/ZnO composite coated polyester nonwoven are shown in Figure $7 \mathrm{~b}, \mathrm{c}$, respectively. It can be seen that two peaks centered at $366.7 \mathrm{eV}$ and $372.7 \mathrm{eV}$ as is shown in Figure $7 \mathrm{~b}$, which can be attributed to $\mathrm{Ag} 3 \mathrm{~d}_{5 / 2}$ and $\mathrm{Ag} 3 \mathrm{~d}_{3 / 2}$, respectively. The difference of binding energy between $3 \mathrm{Ag} 3 d_{5 / 2}$ and $\mathrm{Ag} 3 d_{3 / 2}$ is $6.0 \mathrm{eV}$, which further confirms the formation of elemental silver on the surface of polyester nonwoven [27]. In addition, the peak positions of $\mathrm{Ag} 3 \mathrm{~d}_{5 / 2}$ and $\mathrm{Ag} 3 \mathrm{~d}_{3 / 2}$ are lower than the standard binding energy of $\mathrm{Ag} 3 \mathrm{~d}$ for bulk Ag, which is mainly attributed to the migration of electrons between Ag and $\mathrm{ZnO}$ crystals [21]. In Figure 7c, the O1s profile can be fitted into four peaks. The peak at $530.0 \mathrm{eV}$ and $532.3 \mathrm{eV}$ are attributed to the lattice oxygen and surface hydroxyl oxygen of $\mathrm{ZnO}$, respectively [27]. The peak at $533.7 \mathrm{eV}$ is associate with $\mathrm{C}-\mathrm{O}$ bonds [28]. The peak at $531.0 \mathrm{eV}$ is relate to $\mathrm{C}=\mathrm{O}$ bonds. It is lower than the $\mathrm{C}=\mathrm{O}$ binding energy of the polyester because the charge transfers from the $\mathrm{Ag}$ atom to the $\mathrm{O}=\mathrm{C}$ functional group of the ester group leads to a decrease in binding energy [29]. From Figure 7d, high-resolution XPS spectra of Zn 2p3/2 and Zn 2p1/2 was observed at $1021.6 \mathrm{eV}$ and $1044.8 \mathrm{eV}$. This is similar to the energy band of pure $\mathrm{ZnO}$ nanorods [21], which was also confirmed $\mathrm{ZnO}$ was deposited on the surface of the polyester.

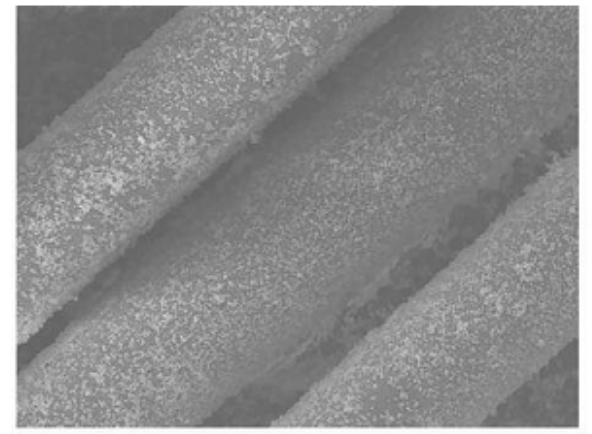

image

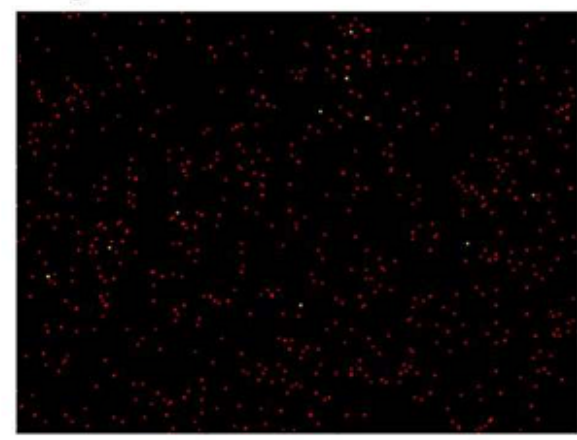

$\mathrm{Zn} \mathrm{Kal}$

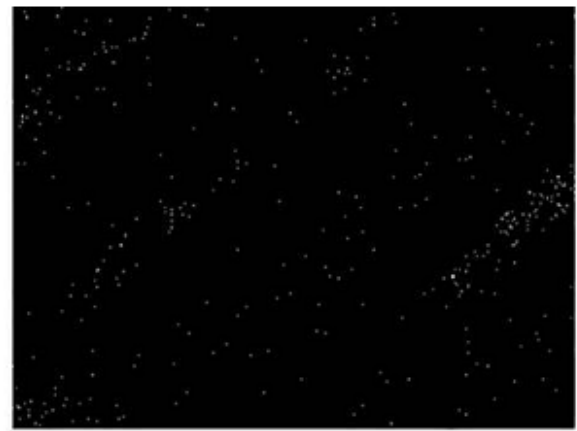

O Kal

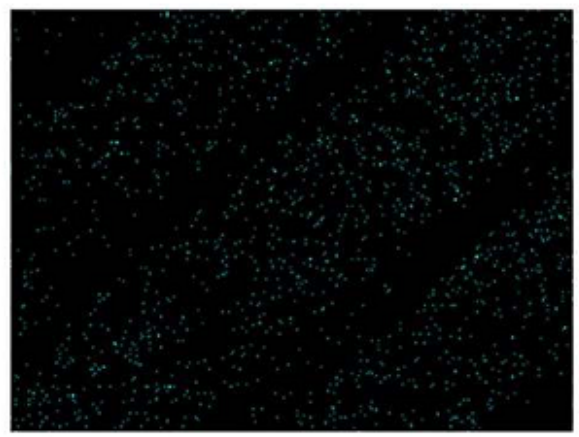

Ag Lal

Figure 6. X-ray mapping images of $\mathrm{ZnO} / \mathrm{Ag}$ composite coated polyester nonwoven (4\#). 


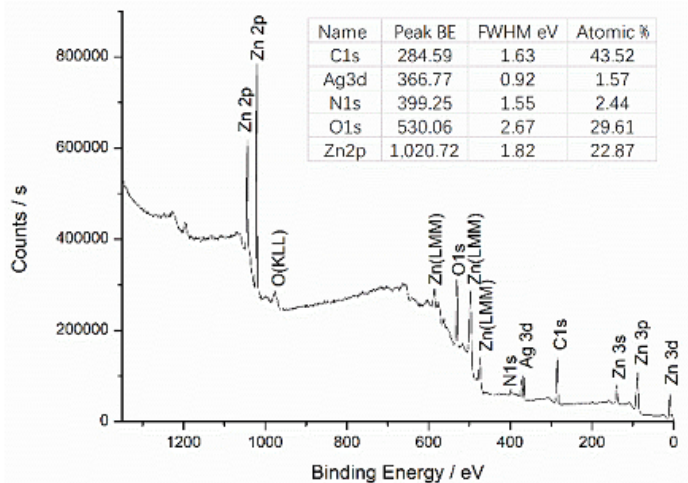

(a)

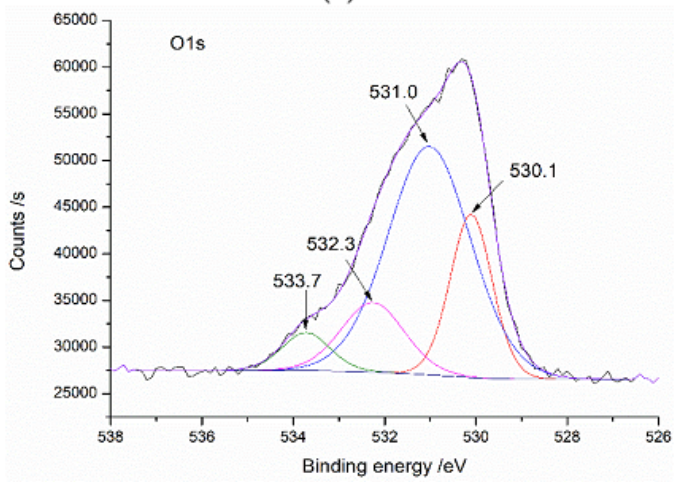

(c)

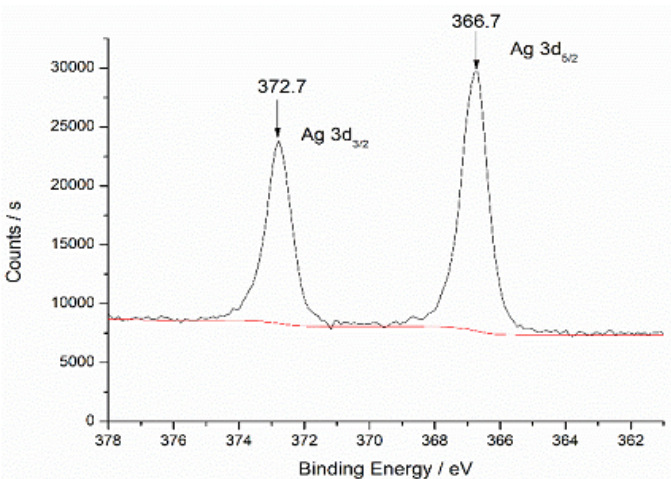

(b)

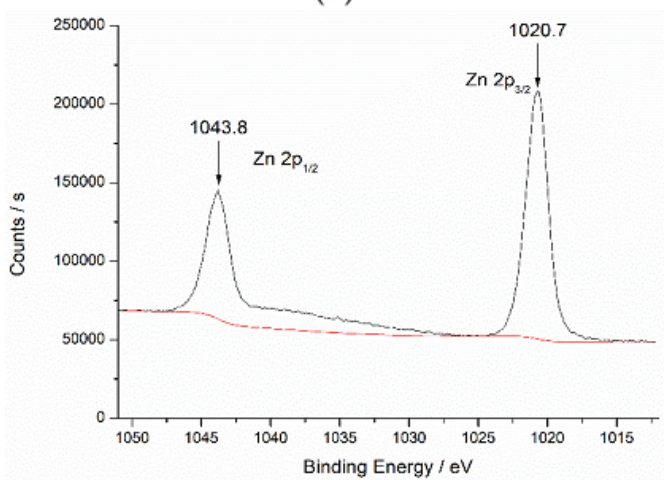

(d)

Figure 7. X-ray photoelectron spectroscopy of $\mathrm{ZnO} / \mathrm{Ag}$ composite coated polyester nonwoven (4\#) (a) full spectrum; (b) Ag3d peak; (c) O1s peak; and (d) Zn2p peak.

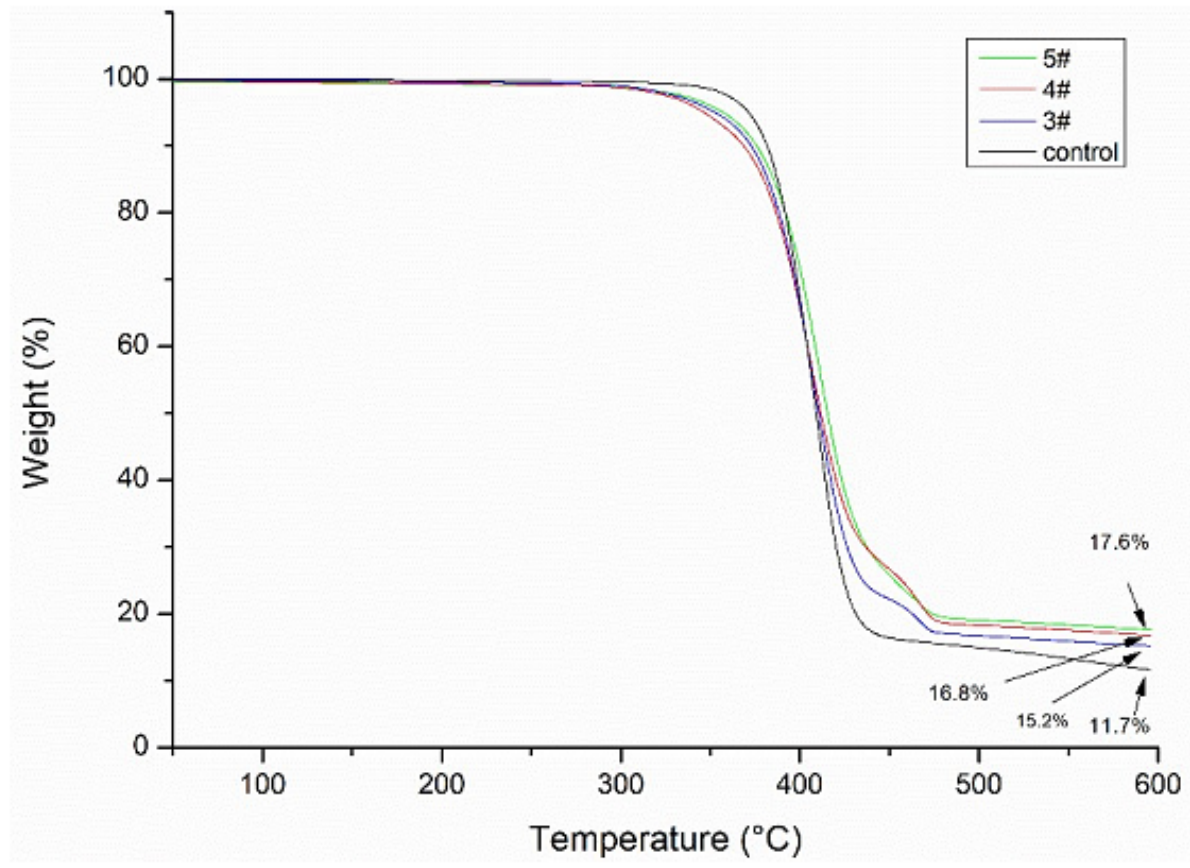

Figure 8. Thermogravimetric (TG) curves of control and $\mathrm{ZnO} / \mathrm{Ag}$ composite coated polyester nonwoven. 


\subsection{Thermogravimetric Analyses}

Figure 8 presents the TG curves for the control sample, $\mathrm{ZnO} / \mathrm{Ag}$ composite coated polyester nonwoven ( $3 \#$ sample, 4\# sample, and 5\# sample). It is clearly observed that the TG curves of the control sample includes one weight loss step. Although that of $\mathrm{ZnO} / \mathrm{Ag}$ composite coated polyester nonwoven includes $50-494{ }^{\circ} \mathrm{C}$ weight loss stages and $494-595^{\circ} \mathrm{C}$ weight loss stages, which can be attributed to the reaction between $\mathrm{ZnO} / \mathrm{Ag}$ composite with polyester thermal decomposition products. The coated polyester nonwoven show an initial loss greater than those of control sample because the triethanolamine treatment causes the macromolecular chain breakage of polyester, which is easily decomposed by heat. In the latter stage, the weight loss of the sample is less than the original. The thermal weight loss of the control sample, 3\# sample, $4 \#$ sample, and $5 \#$ sample at $595{ }^{\circ} \mathrm{C}$ reached $88.3 \%, 84.8 \%, 83.2 \%$, and $82.4 \%$, respectively. This is attributed to the fact that the $\mathrm{ZnO} / \mathrm{Ag}$ composite deposited on the surface of the polyester nonwoven is not easily decomposed, resulting in a reduction in weight loss.

\subsection{Washing Stability Properties}

Weight changes of the $\mathrm{ZnO} / \mathrm{Ag}$ coated polyester nonwoven washed over different time is shown in Table 2. Comparing the samples of 3\#, 4\#, and 5\#, it can be seen that when $0.2 \mathrm{~g}$ silver nitrate was added to the reaction, the weight increase of the treated sample was the highest, reaching $0.0186 \mathrm{~g}$.

This indicates that more $\mathrm{ZnO} / \mathrm{Ag}$ composite are deposited on the surface of the fabric under this condition. After 30 min washing, it was observed that the weight loss of the $4 \#$ sample was the largest and the $5 \#$ sample was the smallest. This is because the $4 \#$ sample forms two layers of different shape particles on the surface of the fiber, the force between the particles is weak, and it falls off easily during washing. However, the surface particles of $5 \#$ sample are sparse, and the particles act directly on the fibers, so the weight loss is minimal. Similar phenomena were also observed on weight loss of the $\mathrm{ZnO} / \mathrm{Ag}$ composite coated polyester nonwoven after $60 \mathrm{~min}$ and $90 \mathrm{~min}$ of washing. However, even if it was washed for $90 \mathrm{~min}$, the $\mathrm{Zn} / \mathrm{Ag}$ composite deposited on the surface of the nonwoven of 3\#, 4\#, and $5 \#$ sample left $0.01 \mathrm{~g}, 0.0094 \mathrm{~g}$, and $0.0129 \mathrm{~g}$, respectively, which was more than half of the surface deposition weight of the polyester nonwoven. This shows that the $\mathrm{ZnO} / \mathrm{Ag}$ composite functional polyester nonwoven prepared by this method has very good washing durability.

Table 2. Weight change for the different washing times.

\begin{tabular}{|c|c|c|c|c|c|c|c|c|}
\hline \multirow[b]{2}{*}{ Sample } & \multirow{2}{*}{$\begin{array}{c}\text { Treated } \\
\text { Weight (g) }\end{array}$} & \multirow{2}{*}{$\begin{array}{l}\text { Treated } \\
\text { Weight } \\
\text { Gain (g) }\end{array}$} & \multicolumn{2}{|c|}{$30 \mathrm{~min}$} & \multicolumn{2}{|c|}{$60 \mathrm{~min}$} & \multicolumn{2}{|c|}{$90 \mathrm{~min}$} \\
\hline & & & $\begin{array}{l}\text { Weight } \\
\text { Loss (g) }\end{array}$ & $\begin{array}{c}\text { Weight } \\
\text { Loss (\%) }\end{array}$ & $\begin{array}{l}\text { Weight } \\
\text { Loss (g) }\end{array}$ & $\begin{array}{c}\text { Weight } \\
\text { Loss (\%) }\end{array}$ & $\begin{array}{l}\text { Weight } \\
\text { Loss (g) }\end{array}$ & $\begin{array}{c}\text { Weight } \\
\text { Loss (\%) }\end{array}$ \\
\hline $3 \#$ & 0.2134 & 0.0152 & 0.0015 & 0.70 & 0.0045 & 2.11 & 0.0052 & 2.44 \\
\hline $4 \#$ & 0.2213 & 0.0186 & 0.0052 & 2.35 & 0.0087 & 3.93 & 0.0092 & 4.16 \\
\hline $5 \#$ & 0.2103 & 0.0162 & 0.0003 & 0.14 & 0.0021 & 1.00 & 0.0033 & 1.57 \\
\hline
\end{tabular}

\subsection{Ultraviolet Resistant Properties}

Table 3 shows the ultraviolet resistant properties of untreated polyester nonwoven and treated polyester nonwoven. From Table 3, it can be observed that the mean UPF of untreated polyester nonwoven is only 14.6. Although the ultraviolet resistant properties of polyester nonwoven increased sharply after $\mathrm{ZnO} / \mathrm{Ag}$ composite coating because the UPF of the lowest coated nonwoven reached 166.8 , which is a result of the strong UV light absorption of $\mathrm{ZnO} / \mathrm{Ag}$ composite for the coated polyester nonwoven. Comparing 3\#, 4\#, and 5\# samples, it can be seen that under the condition of $0.2 \mathrm{~g}$ silver nitrate, the average UPF of the $\mathrm{ZnO} / \mathrm{Ag}$ composite coated nonwoven is higher than that of the condition of $0.1 \mathrm{~g}$ or $0.3 \mathrm{~g}$ silver nitrate. According to the previous thermogravimetric analysis and weighing before the water washing test, this is mainly due to the greater amount of $\mathrm{Zn} / \mathrm{Ag}$ composite coated on the nonwoven surface. 
Table 3. Ultraviolet resistant properties of sample.

\begin{tabular}{cccc}
\hline Sample & Average T(UVA) (\%) & Average T(UVB) (\%) & Average UPF \\
\hline Control & 18.66 & 2.10 & 14.6 \\
3\# & 7.46 & 0.12 & 166.8 \\
$4 \#$ & 5.82 & 0.12 & 219.8 \\
$5 \#$ & 6.22 & 0.14 & 197.4 \\
\hline
\end{tabular}

\subsection{Antibacterial Properties}

Different methods can be used to test the antimicrobial properties of nanocomposite functional materials, such as the agar diffusion plate method and the shake flask method [30]. The agar diffusion plate method checks whether the product has antibacterial properties, while the shake flask method gives more accurate antibacterial results. Therefore, the shake flask method was used to examine the antimicrobial properties of zinc oxide/silver composite coated polyester nonwovens in this study. Figure 9 shows the antibacterial test results of control sample and $\mathrm{ZnO} / \mathrm{Ag}$ composite coated polyester nonwoven after dilution of the bacterial solution 1000 times. From Figure 9a,b, it can be seen that the the control sample inoculated with $S$. aureus bacteria showed bacterial count about $146 \mathrm{CFU}$, while that of treated polyester nonwoven was about 5 CFU. The reduction percentage of Staphylococcus aureus between $\mathrm{ZnO} / \mathrm{Ag}$ composite coated polyester nonwoven and control sample is about $96.6 \%$. Similarly, the count of E. coli colonies cultured with control sample is about $235 \mathrm{CFU}$, and that of E. coli colonies with coated fabric is about $13 \mathrm{CFU}$, as shown in Figure 9c,d. This indicates that the coated fabric has an antibacterial rate of $94.5 \%$ for $E$. coli. These results indicate that $\mathrm{ZnO} / \mathrm{Ag}$ composite functional polyester nonwoven has good antibacterial properties, which are attributed to the inhibition of bacterial growth by the release of $\mathrm{Ag}^{+}$and $\mathrm{Zn}^{2+}$ by the $\mathrm{ZnO} / \mathrm{Ag}$ composite deposited on the polyester nonwoven surface, as well as by the formation of reactive oxygen species on $\mathrm{ZnO}$ surface [31,32].

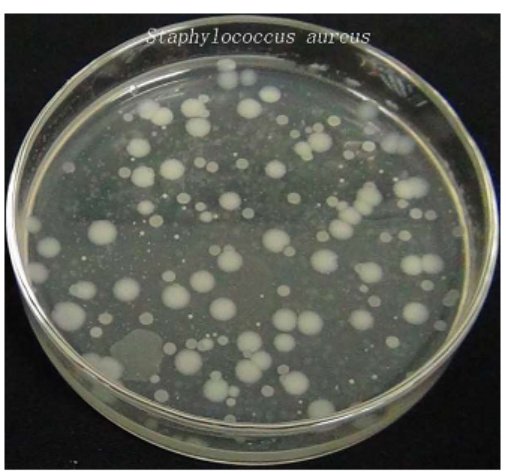

(a)

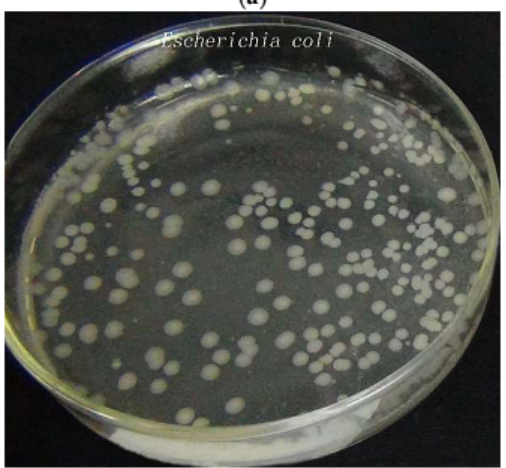

(c)

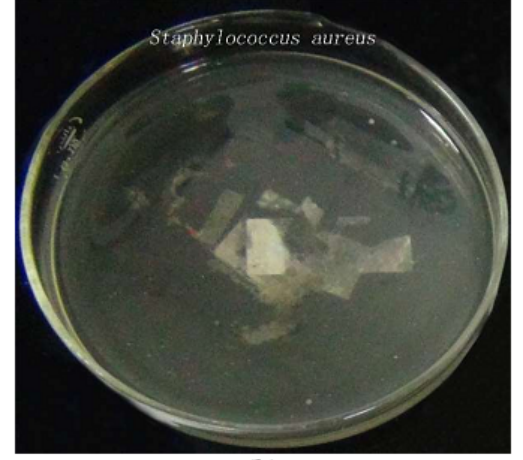

(b)

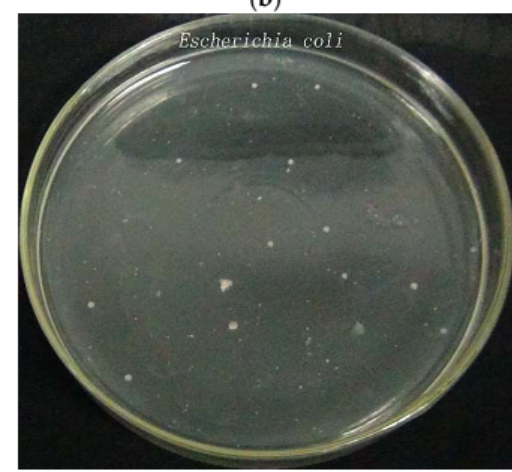

(d)

Figure 9. Shake flask antimicrobial test results of (a) control sample against S. aureus; (b) $\mathrm{ZnO} / \mathrm{Ag}$ coated polyester nonwoven (4\#) against S. aureus; and (c) control sample against E. coli; (d) $\mathrm{ZnO} / \mathrm{Ag}$ coated polyester nonwoven (4\#) against E. coli. 


\section{Conclusions}

The $\mathrm{Ag} / \mathrm{ZnO}$ nanocomposite was successfully deposited on the polyester nonwoven with microwave assistance for $10 \mathrm{~min}$. The experimental results showed that the amount of silver nitrate used in the reaction has an important influence on the morphology and structure of the $\mathrm{Ag} / \mathrm{ZnO}$ composite deposited on the nonwoven surface. The results of TG indicated that the thermal stability of the treated nonwoven was better than that of the control sample because of the deposition of the $\mathrm{ZnO} / \mathrm{Ag}$ composite. The results of the water washing experiment showed that the residual $\mathrm{ZnO} / \mathrm{Ag}$ composite on the nonwoven after washing for $90 \mathrm{~min}$ exceeded half of that of the unwashed nonwoven. UV shielding performance test showed that the $\mathrm{ZnO} / \mathrm{Ag}$ composite coated polyester nonwoven exhibited excellent UV shielding properties, especially when the amount of silver nitrate in the coating was $0.2 \mathrm{~g}$. The results of antibacterial experiments showed that the $\mathrm{ZnO} / \mathrm{Ag}$ composite functional polyester nonwoven has good antibacterial properties. All results indicate that this method has great potential in the production of $\mathrm{Ag} / \mathrm{ZnO}$ composite functional textiles.

Author Contributions: D.S. and Q.W. conceived and designed the experiments; D.S. performed the experiments and wrote the paper; Q.W. revised the paper. All authors read and approved the final manuscript.

Funding: This research was funded by the University natural science foundation of Jiangsu Province grant number [16KJB540004].

Acknowledgments: This research is grateful to the materials and instrument support of Changzhou key laboratory of new textile material and the training of young and middle-aged academic leaders in the Qinglan Project of Jiangsu Province.

Conflicts of Interest: The authors declare no conflict of interest.

\section{References}

1. Yu, L.; Zhang, S.; Liu, W.; Zhu, X.; Chen, X.; Chen, X. Improving the flame retardancy of pet fabric by photo-induced grafting. Polym. Degrad. Stab. 2010, 95, 1934-1942. [CrossRef]

2. Ibănescu, M.; Muşat, V.; Textor, T.; Badilita, V.; Mahltig, B. Photocatalytic and antimicrobial Ag/ZnO nanocomposites for functionalization of textile fabrics. J. Alloys Compd. 2014, 610, 244-249. [CrossRef]

3. Yuan, X.; Xu, W.; Huang, F.; Chen, D.; Wei, Q. Polyester fabric coated with Ag/ ZnO composite film by magnetron sputtering. Appl. Surf. Sci. 2016, 390, 863-869. [CrossRef]

4. Ho Kim, J.; Hwan Lee, J.; Kim, S.-W.; Yoo, Y.-Z.; Seong, T.-Y. Highly flexible ZnO/Ag/ZnO conducting electrode for organic photonic devices. Ceram. Int. 2015, 41, 7146-7150. [CrossRef]

5. Wei, Y.; Ke, L.; Kong, J.; Liu, H.; Jiao, Z.; Lu, X.; Du, H.; Sun, X.W. Enhanced photoelectrochemical water-splitting effect with a bent $\mathrm{ZnO}$ nanorod photo anode decorated with Ag nanoparticles. Nanotechnology 2012, 23, 235401. [CrossRef] [PubMed]

6. Zhang, Q.; Zhao, Y.; Jia, Z.; Qin, Z.; Chu, L.; Yang, J.; Zhang, J.; Huang, W.; Li, X.A. High stable, transparent and conductive $\mathrm{ZnO} / \mathrm{Ag} / \mathrm{ZnO}$ nanofilm electrodes on rigid/flexible substrates. Energies 2016, 9, 443. [CrossRef]

7. Seung, W.; Gupta, M.K.; Lee, K.Y.; Shin, K.S.; Lee, J.H.; Kim, T.Y.; Kim, S.; Lin, J.; Kim, J.H.; Kim, S.W. Nanopatterned textile-based wearable triboelectric nanogenerator. ACS Nano. 2015, 9, 3501-3509. [CrossRef] [PubMed]

8. Kim, J.H.; Kim, D.-S.; Kim, S.-K.; Yoo, Y.-Z.; Hwan Lee, J.; Kim, S.-W.; Seong, T.-Y. Highly flexible Al-doped $\mathrm{ZnO} / \mathrm{Ag} / \mathrm{Al}-$ doped $\mathrm{ZnO}$ multilayer films deposited on PET substrates at room temperature. Ceram. Int. 2016, 42, 3473-3478. [CrossRef]

9. Sarma, B.; Sarma, B.K. Role of residual stress and texture of $\mathrm{ZnO}$ nanocrystals on electro-optical properties of $\mathrm{ZnO} / \mathrm{Ag} / \mathrm{ZnO}$ multilayer transparent conductors. J. Alloys Compd. 2018, 734, 210-219. [CrossRef]

10. Rajabi, M.; Ghorbani, M. Performance evaluation of nanogenerators based on Ag doped ZnO nanorods. Sens. Actuators A Phys. 2017, 266, 338-344. [CrossRef]

11. Mirzaei, A.; Neri, G. Microwave-assisted synthesis of metal oxide nanostructures for gas sensing application: A review. Sens. Actuators B 2016, 237, 749-775. [CrossRef]

12. Li, Y.; Hou, Y.; Zou, Y. Microwave assisted fabrication of nano-ZnO assembled cotton fibers with excellent UV blocking property and water-wash durability. Fibers Polym. 2012, 13, 185-190. [CrossRef] 
13. Tran Thi, V.H.; Lee, B.-K. Development of multifunctional self-cleaning and UV blocking cotton fabric with modification of photoactive $\mathrm{ZnO}$ coating via microwave method. J. Photochem. Photobiol. A 2017, 338, 13-22. [CrossRef]

14. Peng, L.; Guo, R.; Lan, J.; Jiang, S.; Lin, S. Microwave-assisted deposition of silver nanoparticles on bamboo pulp fabric through dopamine functionalization. Appl. Surf. Sci. 2016, 386, 151-159. [CrossRef]

15. Rehan, M.; Mowafi, S.; Abdelmoez Aly, S.; Elshemy, N.S.; Haggag, K. Microwave-heating for in-situ Ag NPs preparation into viscose fibers. Eur. Polym. J. 2017, 86, 68-84. [CrossRef]

16. Poortavasoly, H.; Montazer, M.; Harifi, T. Aminolysis of polyethylene terephthalate surface along with in situ synthesis and stabilizing $\mathrm{ZnO}$ nanoparticles using triethanolamine optimized with response surface methodology. Mater. Sci. Eng. C 2016, 58, 495-503. [CrossRef] [PubMed]

17. Poortavasoly, H.; Montazer, M.; Harifi, T. Simultaneous synthesis of nano silver and activation of polyester producing higher tensile strength aminohydroxylated fiber with antibacterial and hydrophilic properties. RSC Adv. 2014, 4, 46250-46256. [CrossRef]

18. Textiles-Evaluation for Solar Ultraviolet Radiation Protective Properties; Standardization Administration of the People's Republic of China: Beijing, China, 2009; GB/T 18830.

19. Feng, Y.; Shen, J.; Liu, X.; Zhao, Y.; Liang, X.; Huang, J.; Min, J.; Wang, L.; Shi, W. The preparation and optical properties of Ag and Ag/ZnO composite structure. J. Sol Gel Sci. Technol. 2016, 79, 98-106. [CrossRef]

20. Wen, Q.; Dong, L.; Sun, X.; Zhuang, J.; Chen, Z. Preparation of multistage sheet-cluster zno photoanode via a solid state reaction and its property in dsscs. Chem. Res. Chin. Univ. 2016, 32, 437-442. [CrossRef]

21. Liu, H.R.; Shao, G.X.; Zhao, J.F.; Zhang, Z.X.; Zhang, Y.; Liang, J.; Liu, X.G.; Jia, H.S.; Xu, B.S. Worm-like $\mathrm{Ag} / \mathrm{ZnO}$ core-shell heterostructural composites: Fabrication, characterization, and photocatalysis. J. Phys. Chem. C 2012, 116, 16182-16190. [CrossRef]

22. Allahyarzadeh, V.; Montazer, M.; Nejad, N.H.; Samadi, N. In situ synthesis of nano silver on polyester using $\mathrm{NaOH} / \mathrm{Nano} \mathrm{TiO}_{2}$. J. Appl. Polym. Sci. 2013, 129, 892-900. [CrossRef]

23. El-Saftawy, A.A.; Elfalaky, A.; Ragheb, M.S.; Zakhary, S.G. Electron beam induced surface modifications of pet film. Radiat. Phys. Chem. 2014, 102, 96-102. [CrossRef]

24. Kadam, A.N.; Bhopate, D.P.; Kondalkar, V.V.; Majhi, S.M.; Bathula, C.D.; Tran, A.-V.; Lee, S.-W. Facile synthesis of $\mathrm{Ag}-\mathrm{ZnO}$ core-shell nanostructures with enhanced photocatalytic activity. Ind. Eng. Chem. 2018, 61, 78-86. [CrossRef]

25. Sharma, S.K.; Ghodake, G.S.; Kim, D.Y.; Kim, D.-Y.; Thakur, O.P. Synthesis and characterization of hybrid Ag-ZnO nanocomposite for the application of sensor selectivity. Curr. Appl. Phys. 2018, 18, 377-383. [CrossRef]

26. Gozdziewska, M.; Cichowicz, G.; Markowska, K.; Zawada, K.; Megiel, E. Nitroxide-coated silver nanoparticles: Synthesis, surface physicochemistry and antibacterial activity. RSC Adv. 2015, 5, 58403-58415. [CrossRef]

27. Bazant, P.; Kuritka, I.; Munster, L.; Kalina, L. Microwave solvothermal decoration of the cellulose surface by nanostructured hybrid Ag/ZnO particles: A joint XPS, XRD and SEM study. Cellulose 2015, 22, 1275-1293. [CrossRef]

28. Sanaee, Z.; Mohajerzadeh, S.; Zand, K.; Gard, F.S.; Pajouhi, H. Minimizing permeability of pet substrates using oxygen plasma treatment. Appl. Surf. Sci. 2011, 257, 2218-2225. [CrossRef]

29. Gerenser, L.J. Photoemission investigation of silver/poly(ethylene terephthalate) interfacial chemistry: The effect of oxygen-plasma treatment. J. Vac. Sci. Technol. A 1990, 8, 3682-3691. [CrossRef]

30. Krystosiak, P.; Tomaszewski, W.; Megiel, E. High-density polystyrene-grafted silver nanoparticles and their use in the preparation of nanocomposites with antibacterial properties. J. Colloid Interface Sci. 2017, 498, 9-21. [CrossRef] [PubMed]

31. López-Heras, M.; Theodorou, I.G.; Leo, B.F.; Ryan, M.P.; Porter, A.E. Towards understanding the antibacterial activity of ag nanoparticles: Electron microscopy in the analysis of the materials-biology interface in the lung. Environ. Sci. Nano. 2015, 2, 312-326. [CrossRef]

32. Shi, L.E.; Li, Z.H.; Zheng, W.; Zhao, Y.F.; Jin, Y.F.; Tang, Z.X. Synthesis, antibacterial activity, antibacterial mechanism and food applications of $\mathrm{ZnO}$ nanoparticles: A review. Food Addit. Contam. Part A Chem. Anal. Control Expo. Risk Assess 2014, 31, 173-186. [CrossRef] [PubMed]

(C) 2018 by the authors. Licensee MDPI, Basel, Switzerland. This article is an open access article distributed under the terms and conditions of the Creative Commons Attribution (CC BY) license (http:/ / creativecommons.org/licenses/by/4.0/). 